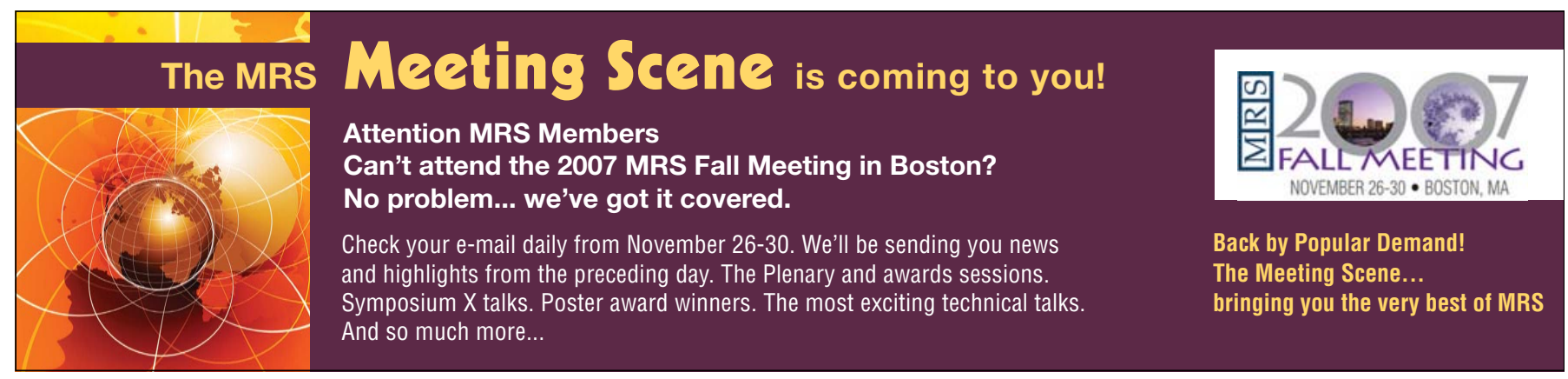

POSTERMINARIES

It is yet another sign that I am aging. More and more often when young researchers hand me a written report of their research, I find myself criticizing their introductory section: "You need to start your literature survey with the original papers on this topic. Go and read..." followed by a citation to some classic of the learned literature.

Literature surveys nowadays rarely seem to extend back in time beyond the horizon of the electronic archives. Of course, electronic archives are reaching deeper into the past all the time, so things are improving, but there is still a horizon set by the fact that many of those pdf files are simply images of the printed pages, and are not "searchable text," except through the archaic ritual of actually reading them.

Heeding my own advice, the other day, I took off the shelf a book that I consider to be a timeless classic of the literature on a particular topic, and I was struck by the title of the second chapter: "Modern Theories of..." The publication date was 50 years ago-1957- and the subject matter is certainly still relevant, but the text of Chapter 2 would appear in a newer book with the heading "Classical Theories...." It is reassuring that the field has made some progress, so what once was modern now is classic.

In materials science, the definition of "modern" is still quaintly time-dependent, but that is not universal. Physics, for example, has evolved a more modern definition of the word "modern," in which Modern Physics includes anything that starts with quantum mechanics or relativity. The first decade of the 20th century will be forever modern, in physics, and the boundary between "modern" and "classi$\mathrm{cal}^{\prime \prime}$ has been established at a fixed point in time. Modern Jazz has a similarly fixed starting point (in the 1940s) defying the dictionary definition: "characteristic of the

\title{
More or Less Modern
}

present time" (OED). What is once declared modern, in these fields, can never become classical, however old it may become. So how can further progress be described? Architecture is yet another case in which "Modern" defines a fixed point in time, marked by the emergence of the minimalist conceptions of Mies van der Rohe and others. Unlike physics and jazz, however, architecture also defines an end of "the Modern." What is more modern than Modern, if you design buildings, is Post-Modern. Oh, what tangled linguistic webs we weave when we abandon the general issue of relativity to the present time in the definition of "modern" —or if we adopt General Relativity as its definition. The areas in which "modern" starts at a permanently fixed point are those that have undergone some kind of revolution, and maybe that is yet to come for materials science. If it does, I shall certainly be relegated to the classical: maybe with a little luck, or a lot of hard work, I could ascend to the status of a "classic."

"In materials science, the
definition of "modern" is still
quaintly time-dependent..."

Or just call me old-fashioned. I am now old enough not to be insulted.

Perhaps it is unreasonable to expect modern apprentice researchers to grasp the full sweep of the literature on their topic, especially if it stretches back 50 years or more. Maybe only the last 10 years, or five, or two is all that counts. After all, Nicholas Murray Butler's definition of an "expert" may be trite, but it is still true: "one who knows more and more about less and less," so why worry about all that ancient history? Isn't the most recent MRS Symposium all you need to know about? Or even less: just the last paper that you wrote, yourself, as you might guess from the citation lists in the works of some authors? Mies van der Rohe, the great prophet of the Modern in architecture, famously said that "less is more," but the "less" to which he referred was the irreducible minimum that is required to define a building, not some fraction of one. Less may be more in your literature survey, but it still needs to be a coherent whole: or to quote Einstein somewhat out of context, make it "as simple as possible, but not one bit simpler."

If you hope that your paper will be a long-lived classic in its own right, it pays not to refer to anyone else's work as "modern," since that can eventually make it look really dated. Still, if you do not care about such timelessness, it is a great shortcut to writing a literature survey, isn't it? "Modern research on this topic includes..." thus absolving yourself from the need to refer to the really classic stuff. Those old guys don't need the citations, and most of them are not in a position to reciprocate with citations to your work, anyway.

Incidentally, I do like to point out that materials science provides a hint of the asymptotic limit of the Butlerian definition of expertise. Those who once strove to know more and more about vacancies, which are small pieces of nothing at all, considered themselves to have the edge on the "less and less" part of the definition. Others, today, work on even smaller "free volumes" of nothingness that can be found in interfaces or the cores of dislocations, so they must be even greater experts. We have become so advanced that we have scales of nothingness to serve as the denominators of our coefficients of expertise. How much less of anything can we know all about, in this modern age, than a fraction of an atomic volume of nothing at all?

Alex KING 